\title{
Author of anti-encryption program faces jail
}

Rex Dalton, San Diego

A Russian graduate student in computer science faces criminal charges for encryption violations this week in the United States, after his arrest at a computer conference.

The arrest on 16 July in Las Vegas, Nevada, of Dmitry Sklyarov, a doctoral student at the Moscow State Technical University, is the latest clash between authorities and computer scientists concerning US laws involving encryption technology and media interests.

Sklyarov is in trouble not for what he said in his talk, but for his role in promoting encryption-busting software. Groups supporting more free access to encryption technology nonetheless condemned the arrest, which was carried out by the Fed- eral Bureau of Investigation (FBI) at the Defcon-9 conference of computer scientists and hackers.

If convicted by the federal court in San Jose, California, Sklyarov faces a fine of up to $\$ 500,000$ or a maximum of five years in prison. He was investigated by a federal 'high-tech squad' of agents based in San Jose. At a meeting with computer-industry executives in Silicon Valley on 20 July, John Ashcroft, the US attorney, said he plans to set up more of these squads throughout the United States.

Sklyarov faces a felony charge of "trafficking in a product designed to circumvent copyright protection measures" in violation of the 1998 Digital Millennium Copyright Act. He is the author of a computer program

\section{NASA mission has wind in its sails}

William Triplett, Washington

With the launch on 30 July of its Genesis spacecraft, researchers at NASA's Jet Propulsion Laboratory in Pasadena, California, will begin a three-year, \$209-million study of the origin of the Solar System.

A Delta II rocket will take Genesis about a million miles from the Earth, to a position from which it will fly in a series of loops to collect particles from the solar wind. These will be sorted on board

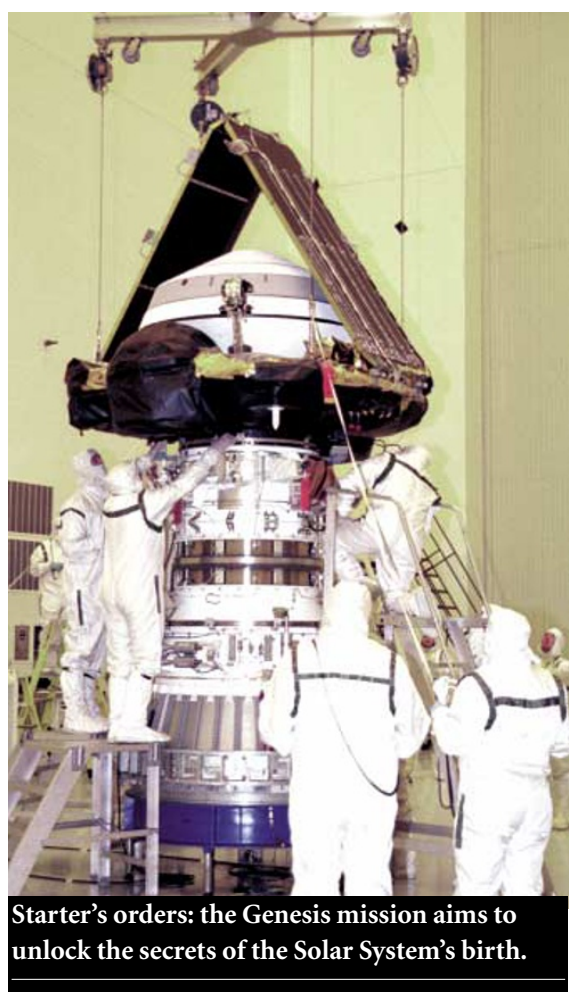

and brought back to Earth for analysis.

The haul, mainly of ions that have drifted away from the Sun's outer atmosphere into space, is expected to contain evidence of the solar nebula that marked the beginning of the Solar System around five billion years ago.

"The outer layer of the Sun preserves a fossil record of the chemical and isotopic composition of the solar nebula, the disk of gas and dust from which all the planets formed," explains Donald Burnett of the California Institute of Technology, the principle investigator on the Genesis mission. The solar nebula is important, he says, because it was the transition phase between when "everything was just stardust" and the matter that now makes up the Solar System. If it succeeds, Genesis will provide insight into what happened during that transition.

John Leibacher of the National Solar Observatory in Tucson, Arizona, chairman of the American Astronomical Society's solar physics division, says that the materials in the solar wind "haven't undergone significant nuclear transformation in five billion years".

Some of the Apollo Moon missions captured solar wind, but on a much smaller scale. Genesis will capture 10-20 micrograms of material over two years, using four instruments: collector arrays, an ion monitor, an electron monitor and an ion concentrator. "We have much purer materials to collect solar wind in now and we have much greater analytical capabilities," says Burnett.

NASA also plans a spectacular homecoming for Genesis. Concerned that a parachute landing could disturb the samples, the agency will deploy helicopters to capture the spacecraft as it floats down. http://genesismission.jpl.nasa.gov

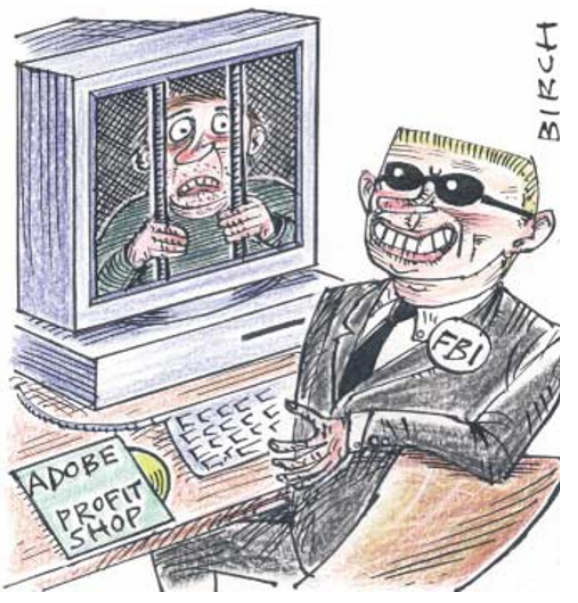

called the Advanced eBook Processor that is distributed by a Moscow-based firm, ElcomSoft. ElcomSoft circumvents the encryption of a program - the Adobe Acrobat eBook Reader - sold by San Jose-based Adobe.

Adobe security officials told FBI agents on 26 June that the ElcomSoft program converts their encrypted product into a 'naked file' in standard portable document format (PDF) that could be transferred to anyone, and explained how this would hurt Adobe's business. A criminal complaint was issued on 7 July, with agents arresting Sklyarov after his talk on the "password protection aspects of electronic books and documents ... and PDF format".

"His speech was simply a part of his doctoral work," says Alexander Katalov, ElcomSoft's president, who was in California last week seeking Sklyarov's release on bail. Katalov says that another Russian ElcomSoft employee was held briefly in Las Vegas, but was allowed to return to Moscow.

The San Francisco-based Electronic Frontier Foundation (EFF) criticized Sklyarov's arrest and planned a series of protests on 23 July. In a statement, EFF's executive director Shari Steele complained of "shameful and opportunistic actions against an individual who was here simply to share his knowledge and technical expertise with American scientists".

The EFF is also helping Princeton University computer scientist Ed Felten and colleagues with their legal battle to publish encryption techniques involving music files (see Nature 411, 5; 2001). Felten has asked the federal court in San Jose for permission to publish an article that the Recording Industry Association of America, a trade group, asserts will damage music distributors.

The Russian consulate in San Francisco says it has been in contact with Sklyarov in jail, and that he was well and was being provided appropriate legal rights. Adobe officials declined to comment. 